\title{
Progress on laser plasma accelerator development using transversely and longitudinally shaped plasmas
}

\author{
Wim P. Leemans ${ }^{\mathrm{a}, \mathrm{b}, *}$, E. Esarey ${ }^{\mathrm{a}, \mathrm{b}}$, C.G.R. Geddes ${ }^{\mathrm{a}}$, Cs. Toth ${ }^{\mathrm{a}}$, C.B. Schroeder ${ }^{\mathrm{a}}$, \\ K. Nakamura ${ }^{\text {atb }}$, A.J. Gonsalves ${ }^{\text {a }}$, D. Panasenko ${ }^{\text {a }}$, E. Cormier-Michel ${ }^{\mathrm{a}}$, G.R. Plateau ${ }^{\mathrm{a}, \mathrm{c}}$, \\ C. Lin ${ }^{\text {a,d }}$, D.L. Bruhwiler ${ }^{e}$, J.R. Cary ${ }^{\mathrm{e}, \mathrm{s}}$ \\ a Lawrente Berktey Nattont Laboratory, Berkelej, CA 94720, USA \\ b Utiversily of Neroda, Reno, NV \$9557, USA

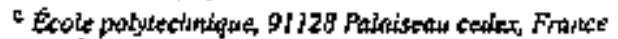

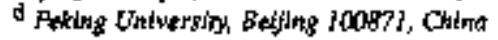 \\ - Terll.X Carporation, Bander, CO g0303, USA \\ ${ }^{f}$ Un'wersity of Colorado, Bowder, CO 800309, USA
}

\begin{abstract}
A summary of progress at Lawrence Berkeley National Laboralory is given od: (1) experimeats on down-ramp injoction; (2) experiments on acceleration in eapilary discharge plasma channets; and (3) simulations of a staged laser wakefield accelerator (LWFA). Control of trapping in a LWFA using plasta density down-tamps produced electron bunches with absolute longtivdinal and transverse momentum spreads more than tea times lower than in previous experiments 20.17 and $0.02 \mathrm{MeV} / \mathrm{c}$ FWHM, respectively) and with central monenta of $0.76 \pm 0.62 \mathrm{MeV} / \mathrm{c}$, stable over a week of operatton. Experiments wete also carritat int using a $40 \mathrm{TW}$ leser interacting with a hydrogen-filed capillary discharge waveguide. For a $15 \mathrm{~mm}$ long, 200 wr dianeter capillary. quasi-monoenergetic bunches up to $300 \mathrm{MeV}$ were observed. By detuning discharge delay from optirnum guiding performance, self-trapping was found to be stabilizex For a $33 \mathrm{~mm}$ long, 300 um capillary, a paranneter regime with high energy butches, up ta $1 \mathrm{GeV}$, wis found In this regime, peak electron energy was conclated with the amount of trapped charge. Simulations stow that bunches produced on a dowa-ramn and iniected into a channel-guided LWFA can produce stable beams with $0.2 \mathrm{MeV} / \mathrm{c}-\mathrm{cl}$.t5s momentum spread at high energies.
\end{abstract}

\section{REsumet}

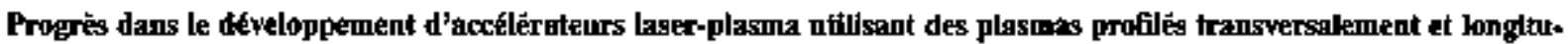
dinglement. On présente un résumé des progrầs obtepus au Lawrence Berkeley Natlonal Laboratory sut : (1) les expétientes sur l'injection dans une rampe de densité décroissante ; (2) les expériences sur l'accelération dans des canaux de plasmas de décharges capilaires; et (3) les simulations d"accélérateur par champ de sullage laser (LWFA) en configuration multi-étaget. Le contrỉle du piégeage dank un LWFA a l'alde de rampes de derisité décroissante produit des paqueto d'elestronts avec des dispersions de mo. ment cinétique longitudinal et transversal plus de dix fois plus faibles que dans des expériences antérieures (respectivement 0,17 and $0,02 \mathrm{MeV} / \mathrm{c}$ FWHM) avec une yaleur centrale de $0,76 \pm 0,02 \mathrm{MeV} / \mathrm{c}$ srable sur Ia durfe de la semalite d'experlence. Des expériences ont également été faites à l'ajde d'un laser de $\mathbf{4 0}$ TW interagissant avec vo guide d'onde constitué pas une décharge

+ Corresponding aulbor.

E-rritif adifress: WPLeemansolbl.gov (W.P. Leemans). 


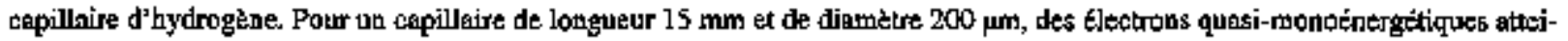
gant $300 \mathrm{MeV}$ ont sté observís. En jouant sur le delai du tomps d'allumage de la déchange et en s'écartant ainsi des performances

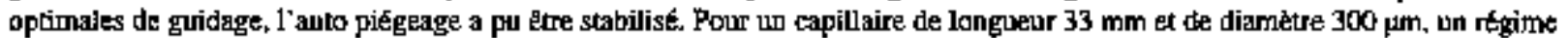

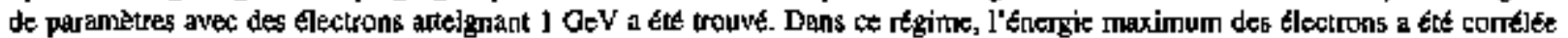
avec la quantite d'electrons piéghs. Les simulations ont montré que des paquets d'electrons produits dans une rampe de dentití

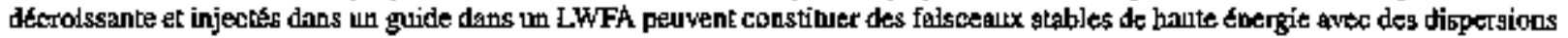
en mornest de l'otde de $0,2 \mathrm{M}+\mathrm{V} / \mathrm{c}$.

Keywords: Laser-driwer electron atcelestation

Mots-etes: Accilétation laser d'electrans

\section{Introduction}

Laser wakefield accelerators (LWFAs) have demonstrated high field gradients, up to humtheds of $G \mathrm{G} / \mathrm{m}$, Teducing accelerating distances by a thousandfold compared to conventional technologies [1]. The laser ponderomotive (radiation) pressure drives a plasma density wave (wake), whose longitudinal field can "self-trap" and accelerate electrons from the plasma. Self-trapped LWFA experiments prodwced bunches with few MeV/c momentum spreads near $100 \mathrm{MeV} / \mathrm{c}$ by extending the Jaser propagation distence using a guiding channe] [2] or large spot \$ize [3,4]. Channel guided LWFAs subsequently produced bunches with $\sim 20 \mathrm{MeV} / \mathrm{c}$ longitudinal and $2 \mathrm{MeV} / \mathrm{c}$ tansverse momentum spread at $1 \mathrm{GeV}$ and stable bunches at $500 \mathrm{MeV}[5,6]$.

In self-trapped experiments, injection, acceleration, and guiding are interdependent, which limits tunability and control of the electron banch quality. Bunch quality was best when operating at the trapping threshold $[3,4,6,7]$, and relatively stable operation $[5,6,8]$ was only observed in a narrow parameter window. The plasmas used bad approximately constant density along the laser propagation direction, so that the wake phase velociry $v_{\phi}$ was $\sim v_{g}$ (the laser group velocity [1]). Using lower plasma density increases $v_{g}$ and hence $v_{\phi_{+}}$allowing electrons to accelerate to higher energies while remaining in phase with the wake [3-5]. However, for given laser parameters, no self-trapping is observed below a minimum density [3-5], indicating the need for extemally controlled injection.

Independent control of electron injection into the wake and of the accelerating struchure could increase bunch energy by allowing operation of the accelerator at Iower density, while also improving stability and quality by allowing independent tuning of injection. This is important for many applications, which desire monentum spreads below those of present experiments ( $1-20 \mathrm{MeV} / \mathrm{c}$ or few longitudinal spread and $\sim 0.2-2 \mathrm{MeV} / \mathrm{c}$ transverse spread). The short plasma wave wavelength $\lambda_{p}=\sqrt{\pi c^{2} m / e^{2} n_{e}}$, typically $\sim 10-100 \mu \mathrm{m}$, determines the size requirement for the injected bunch, where $n_{\varepsilon}$ is the plasma density.

Two possib]e laser-based methods for electron injection are collising pulse injection [9-11] and down-ranp injection [12]. In colliding pulse injection, additional laser pulses are used to boost the momenturn of a group of plasma electrons, allowing them to become trapped in the wake. In down-ramp injection, a decreasing plasma density in the direction of laser propagation is used to slow the plasma wave phase velocity such that localized trapping occurs. Experiments [13] have demonstrated controlled injection using the colliding polse method and showed tuning of the electron energy by changing the injection location within the plasma. Down-ramp injection experinents have also demonstrated the production of electron bunches with smalt absolute energy spread [14].

Future LWFA experiments are likely to use a staged approach [15]. In the first stage - the injection stage - a relatively low energy, high quality electron bunch is geterated using a laser injection method. In the second (and subsequent) atages, this high quality bunch is accelerated to high energits in a "dark cturent fres" (no additional trapping) mantrer, while preserving the low emitlance and low absolnte energy spread of the injected bonch.

In this article we report on progress at the Lawrence Berkeley National Laboratory (LBNL) on (1) experimental sturies of down-ramp injection, (2) experimental studies of self-trapping and acceleration in capillary discharge plasma channels, and (3) numerical studies using particle-in-cell sinulations of a staged LWFA. 


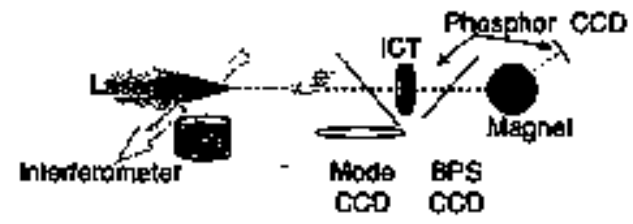

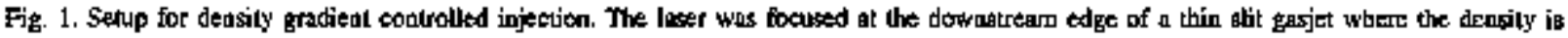

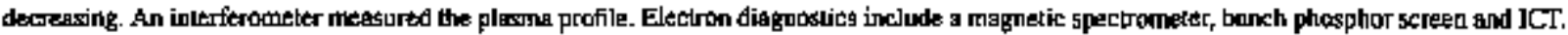

\section{Experiments on down-ramp injection}

Plasma density gradients with density decreasing in the laser propagation direction (down ramps) have been proposed to control trapping. In such gradients $\lambda_{p}$ increases with propgation, causing the wake fronts behind the Jaser to tall further behind as the laser propagates which decreases the wake phase front velocity $v_{\phi}[12,16-18]$. Use of the gradient separates density (which controls resonance of the plasma wave with laser pulse length [1]) from wake phase velacity $y_{+}$and controls wake phase velocity as a function of propagation distance. The reduced $v_{\phi}$ reduces the threshold for trapping by reducing the velocity electrons must achieve to be trapped, and hence allows trapping at lower densities than in uniform plasmas. Such nuning of the trapping threshold has been shown to produce stable electron bunches with an order of magnitude lower absolute momentum spread than other LWFA experiments [14]. The reduced phase velocity also reduces the maximum energy gain however because dephasing occurs quickly. Hence for stable high energy bunches a down ramp region to control trapping should be followed by a long uniform-density plasma for acceleration to high energy.

The experimental setup is displayed in Fig. ${ }_{\text {, }}$ showing a pulse from the LOASIS Ti:Sapphire laser [19] focused on the downstream edge of a thin slit gas jet oriented taansversely to the laser axis. The laser ionized the bydrogen gas and drove a plasma wake. Peak laser power was $10 \mathrm{TW}$ (0.5 J in 47 ts FWHM), focused to a 7.5 $\mu \mathrm{m}$ FWHM spot. The plasma density profile in the lașer propagation direcion was measured to be Gaussian for densities above the interferometer measurement threshold of $\sim 2 \times 10^{18} \mathrm{~cm}^{-3}$, with a peak density of $2.2 \pm 0.3 \times 10^{19} \mathrm{~cm}^{-3}$ and a FWHM of $750 \mu \mathrm{m} \pm 100 \mu \mathrm{m}$. Simulations show that the wake is excited sirongly within a Rayleigh range $Z_{R} \sim 200 \mu \mathrm{m}$ of the laser focus, a small fraction of the jet lengh. This allowed effective selection of the densiry gractient where the wake is excited, and hence control of trapping, using laser focus locetion [14]. Focusing upstream of the jut center produced an increasing or flat density, and electron spectra in this regime have been published previously, showing exponential energy spectra and fluctuating quasi-monoenergetic peaks from self-modulated acceleration [7]. Focusing downstream produced a decreasing density. Electron bunches were characterized by a magnetic spectrometer. The bunch was bent $55^{\circ}$ onto a phosphor screen (LANEX) imaged by a CCD, which imaged a momentum range of $\pm 14 \%$ about a central momentum determined by the magnet cument. Mornentum resolution was $\pm 5 \%$. Bean divergence was observed in the out-of-plane direction. Alternatively, divergence and profile in both planes was observed by an insertable bunch phosphor screen (BPS). Charge was determined by cross-comelating the phosphor signals with an integrating current tranfformer (ICT). Transmitted laser mode and THz bunch length measurements were presented in [14].

Focusing at the downstream edge of the jet, in the density down ramp, produced e] lectron bunches with an order of magnitude lower absolute momentum spread and jitter than previously observed in LWFAs [14], and multiple datasets on different run days showed that accelerator operation was stable and tepealable over a week of operation. Magnetic spectrometer dataset $A$ (Fig. 2) showed bunches with central momentum stable at $0.76 \mathrm{MeV} / \mathrm{c} \pm 0.02 \mathrm{MtV} / \mathrm{c} \mathrm{RMS}$ and with momentum spread stable at $0.17 \mathrm{MeV} / \mathrm{c}$ FWHM (20\%) $\pm 0.02 \mathrm{MeV} / \mathrm{c} \mathrm{RMS} \mathrm{over} 28$ sequential and 45 total diagnostic shots. In the undispersed plane, the bunch divergence was $20 \mathrm{mrad}$ FWHM $\pm 1.8 \mathrm{mrad} R M 3$, and pointing deviation was 1.5 mrad RMS.

Burch divergence in both planes (momentum integrated) was measured on the insertable BPS phosphor (Fig. 3) [20]. A small-divergence bunch is visible sumounded by a broad background. The small-divergence feature has a divergence of 26 (14) mrad in the horizontal (vertical) plant with RMS deviations of \pm 1.8 (2.5) mrad over 31 shots. Bunch pointing showed 1.8 (1.2) mrad RMS and 8 (5) mrad ptak-to-peak deviations in the horizontal (vertical) plate. Deviations in pointing and divergenee are much Iess than the beam divergence. Vortical data agree with measurements from the magnelic spectrometer, indicating thal the nanrow feature is the MeV bunch The broad 

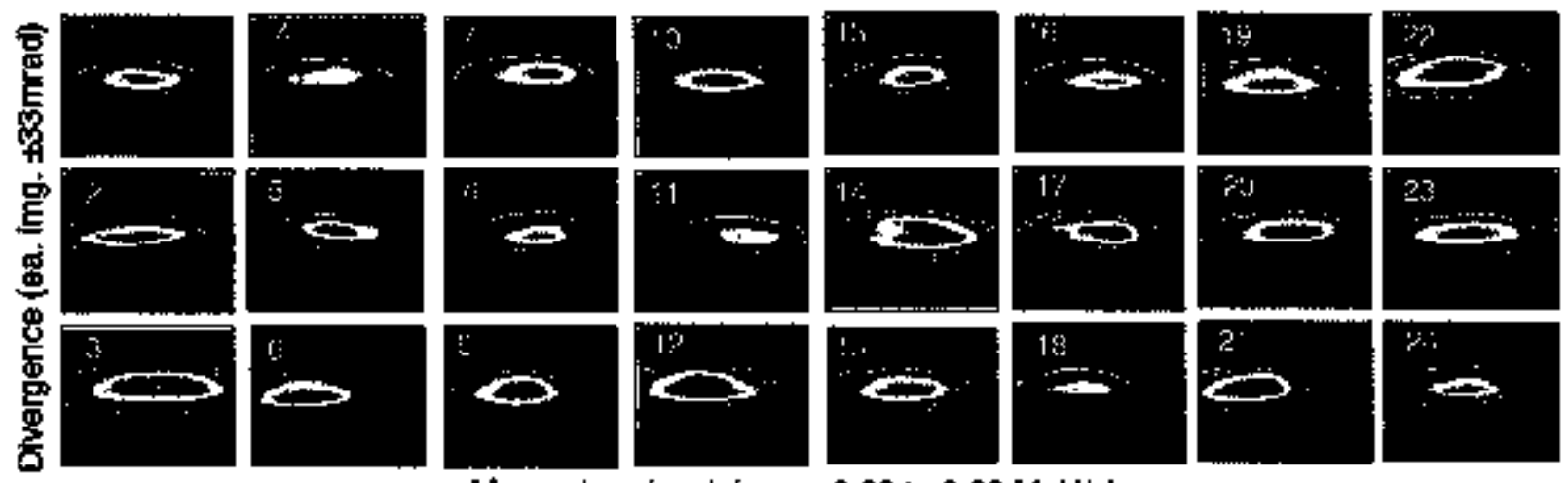

Momentum (each image 0.66 to $0.88 \mathrm{MeV} / \mathrm{c}$ ) $\rightarrow$

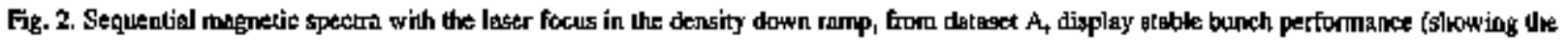

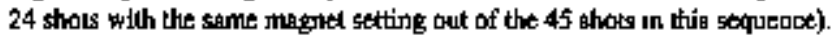
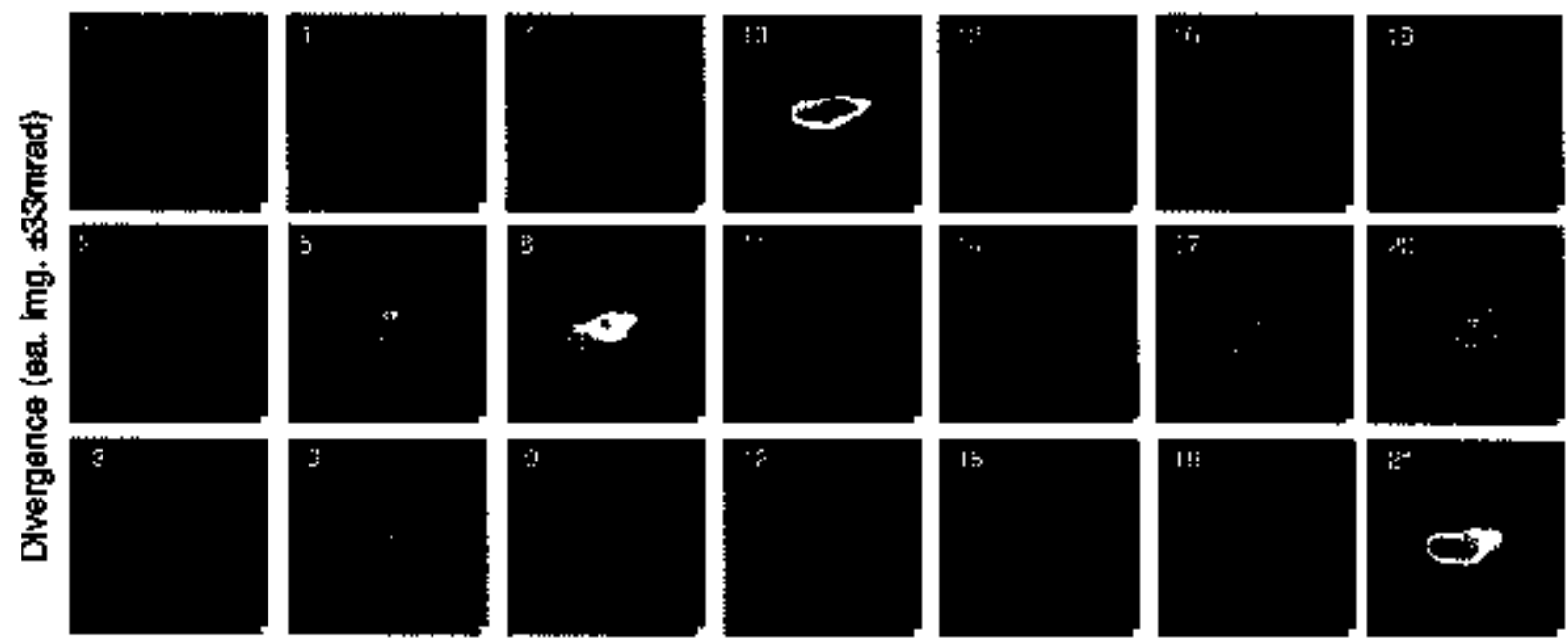

Divergence (ea. img. $\pm 33 \mathrm{mrad})$

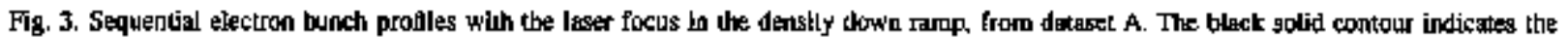

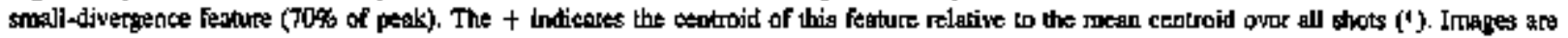
ploted on a fixed scale to stow charge vatiatton and stabillty (showing 21 of the 31 ghatg in this sequence).

background is likely lower momentum electrons. The observed divergence indicates transverse bunch momenta of $\sim 0.02 \mathrm{MeV} / \mathrm{c}$, much lower than the $0.3-2 \mathrm{MeV} / \mathrm{c}$ in conventional self-trapped experiments $[2,5]$.

The signals on the magnetic spectrometer and the narrow divergence feature on the BPS phosphor were conrelated to ICT charge measurements to extract the charge of the bunch at $0.76 \mathrm{MeV} / \mathrm{c}$. This gave $Q_{\text {bunch }}$ of $0.3-1 \mathrm{nC}$. Charge stability was $40 \%$ RMS in this dalaset.

The central momentum was stable between 0.76 and $0.78 \mathrm{MeV} / \mathrm{c}$, FWEM entrgy spread between 0.16 and $0.19 \mathrm{MeV} / \mathrm{c}$, and divergence between 17 to 23 mrad over three nus and over a week of clock time. Fig. 4 shows data from a second sequence of 82 shots (set B), measured 123 hours after Fig. 2, demonstrating this stability. This will be important for LWFA applications and has not been previousiy observed. Charge stability as good as $15 \%$ RMS was observed. Variation in charge stability from nun to nu is likely due to diurnal variation in laser stability and prepulse.

In the data presented in Figs. 2 and 4, , $10 \mu \mathrm{m}$ silver coated nitrocellulose pellicle transmitted the electron bunch and divested the laser to a mode imager CCD [21] to measure the laser profile at the plasma exit [14]. A third set of 60 shots (datoset C) taken immediately snbsequent to that shown in Fig. 4 and with the mode imaget pellicle 


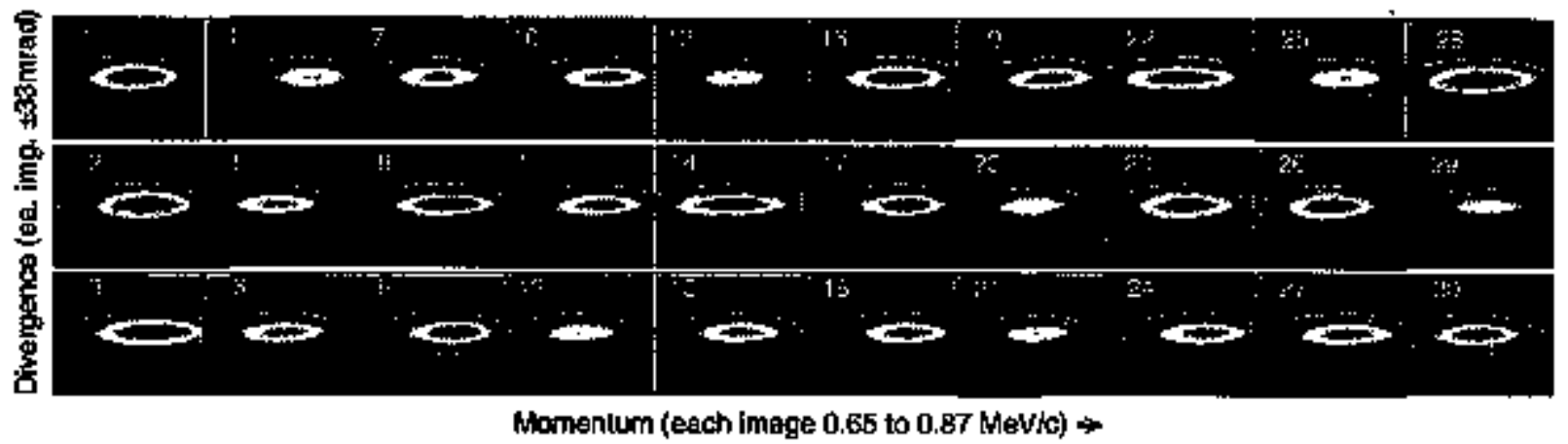

Fig. 4. Sequential magnetic spectra with the laser focus in the density dowa ramp from run B, 123 bours after run A (ahowing 30 Ghotg with the same magnet setthe out of 82 shots in the sequecoe).
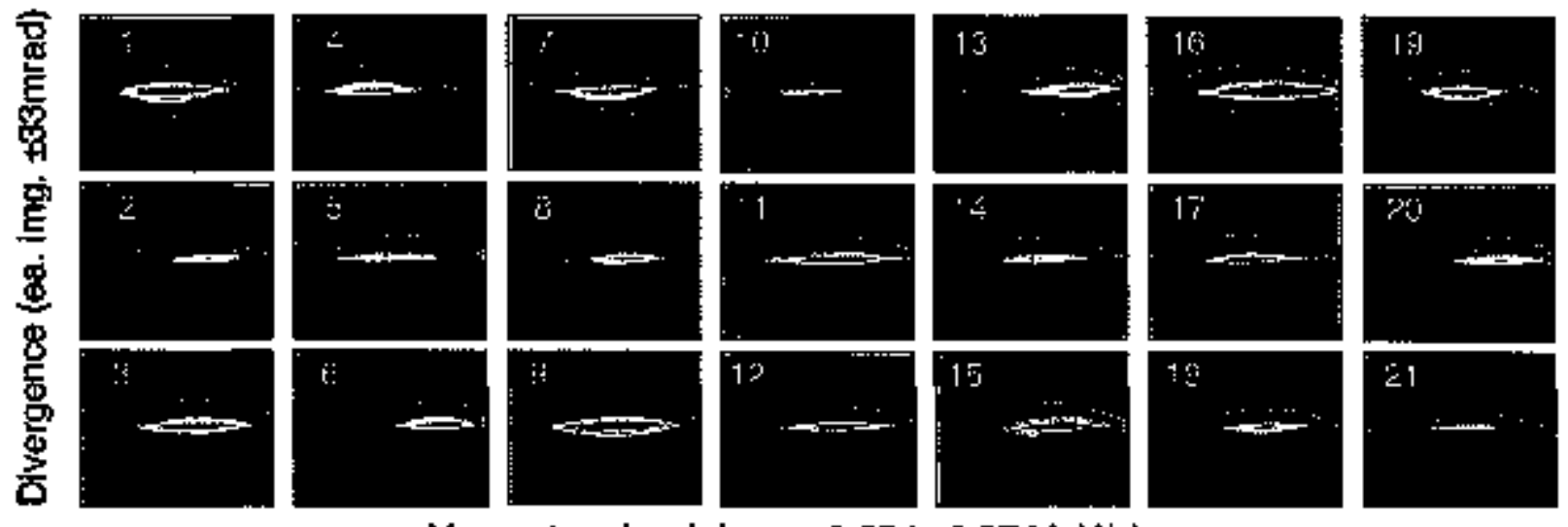

Momentum (each image 0.65 to $0.87 \mathrm{MeV} / \mathrm{c}) \rightarrow$

Pig. 5. Sequenlial magnetic spexdri with the lnser focus in the deasity down ramp, and will the mode imager pellicle reroned from the beam, from

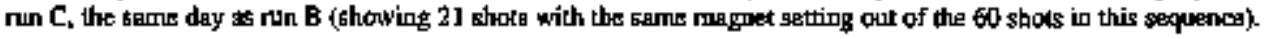

removed, is displayed in Fig. S. Visible is a reduction in FWHM divergence by $10-20 \%$, and appearance of a narrow divergence feature (6 mrad) at the $80 \%$ contour, indicating that scattering contributed modestly to beam divergence in the measumenents, and showing that there is a sub-popolation of electrons with lower divergence. Longitudinal momentum spread was not affected.

\section{Experignents on acceleration with capillary discharge plasma channels}

In the first generation of capiliary discharge guided LWFA experiments [5,6], accelerator performance was found to exhibit a complicated and sensitive interdependence on input laser and plasma parameters. Thesse parameters included the delay between the onset of the discharge current and arrival of the Iaser bean (discharge delay $t_{d}$ ), the estimated on-axis plasma density $n_{0}[22]$, the peak Iaser power $P$, and the capillary diameter. Electron beams with energies of $1 \mathrm{GeV}$ were obtained in a $33 \mathrm{~mm}$ long, $300 \mu$ diameter capillary for $P \sim 42 \mathrm{TW}$ and $n_{0}=4.3 \times 10^{18} \mathrm{~cm}^{-3}$. Although $1 \mathrm{GeV}$ beam generation was not stable, a statistical analysis did show a parameter regime where $0.5 \mathrm{GeV}$ e-beans were prodnced with improved stability by tightly controlling the input parameters for a $33 \mathrm{~mm}$ long, 225 um diameter capillary.

In order to design a next generation apparabus for stable prodaction of higher quality e-beams, with small emittance and high energy end charge, it is critical to untangle this interdependence of input laser and plasma parameters, which requires further parameter exploration and analysis. We next present a performtance andlysis of the capillary discharge guided LWFA using a $15 \mathrm{~mm}$ long, $200 \mu \mathrm{m}$ diameter and a $33 \mathrm{~mm}$ long, $300 \mu \mathrm{m}$ diameter capillary. Exptriments varying capillary length give insight into the trapping and dephasing physics of the capillary discharge guided LWFA. 


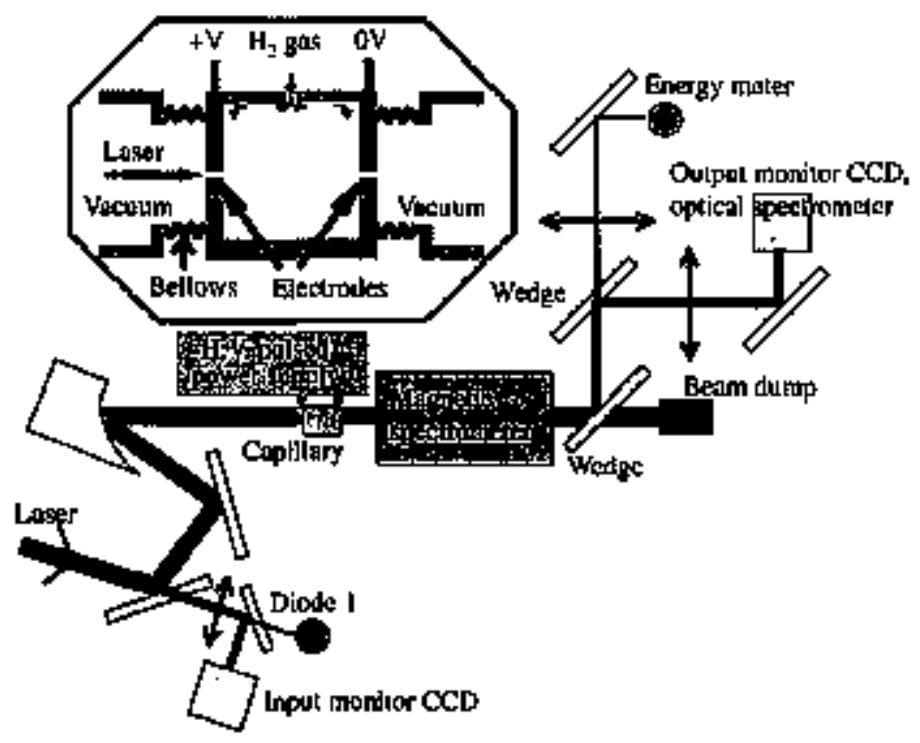

Fig 6. Schematic diagram of the capillary chscharge-puhded laser wakefleld accelerator and diagnostics. A demt of the Gapillary tischarge unit is th the upper insert and that of the electron spectroneter can be found in Ref. [23]

The schematic of the capillary discharge guided LWFA experiments is shown in Fig. 6. The laser that was uilized was the shorl pulse, high peak power and bieh repetition rate $(10 \mathrm{~Hz}) \mathrm{Ti}: \mathrm{Al}_{2} \mathrm{O}_{3}$ laser system of the LOASIS facility at LBNL. The laser beam was focused onto the entrance of a cnpillary discherge waveguide by an $\mathrm{f} / 25$ off-axis parabolic mìroc. A typical focal spot șize (or waist) was $r_{0} \simeq 25 \mu \mathrm{m}$ containing $60 \%$ of the laser energy. Here, a Gaussian transwerse profile of $I=I_{0} \exp \left(-2 r^{2} / r_{0}^{2}\right)$ is assumed. Full energy and optimum compression gives $P=43 \mathrm{TW}$ ( $\varepsilon_{i n} \approx 40$ fs for the FWHM of the intensity pusse), calculated peak intensity $I_{0}=2 P / \pi r_{0}^{2}=2.6 \times 10^{18} \mathrm{~W} / \mathrm{cm}^{2}$, and a nomalized vector potential $\left.a_{0} \simeq 8.6 \times 10^{-10} \lambda[\mathrm{\mu m}]\right]^{1 / 2}\left[\mathrm{~W} / \mathrm{cm}^{2}\right] \simeq 1.1$.

The capillary waveguide was laser-machined in a sapphire plate. Hydrogen gas was intoduced into the capillery using two gas slots as shown in Fig. 6 (inserl). A discharge was struck between electrodes located at each end of the waveguide, using a high voltage pulsed power supply with a $4 \mathrm{nF}$ capacitor charged to between 15 and $18 \mathrm{kV}$. Measurements showed that a fully ionized, approximately parabolic channel was formed on axis [22]. This fully ionized feature was also confimed by the absence of ionization induced blueshifting of the transeritted laser spectrum when a low power $(\leftarrow 0.2 \mathrm{TW})$ jaser pulse was guided,

The electron beams generated werc characterized by an electron spectometer ublizing a ronod dipole magnet with a maximum magnetic field of $1.25 \mathrm{~T}$ and effective radius of $195 \mathrm{~mm}$. The magnetic spectrometer allowed simultaneous measurement of the laser pulse and e-beam dus to its large gap, and single shot measurement of electrons from $0.01 \mathrm{GeV}$ to $0.14 \mathrm{GeV}$ (bottom view) and $0.17 \mathrm{GeV}$ to $1.1 \mathrm{GeV}$ (forward view) [23]. The laser energy was monitored both before and after the interaction to evaluate the guiding efficiency and guided beam quality. The laser output spectrum was measured by a broadband optical spectrometer which covers a wavelength range of 320 to $1000 \mathrm{~nm}$ in a single shot.

In experiments using a $15 \mathrm{~mm}$ long, $200 \mu \mathrm{m}$ diameter capillary, the guiding performance and e-beam generation showed clear dependence on the discharge delay. Shown in Fig. 7(a) are the discharge delay dependence of several binned optical spectra. The center is defined as the light within the frequency bandwidth of $770 \leqslant \lambda \leqslant 835$ nm, and 100\% of incident light was within this band. The red (blue) shift is tefined as $835<\lambda<1100 \mathrm{~nm}(320<\lambda<770 \mathrm{~nm})$. The input laser parameters were $0.9 \mathrm{~J}( \pm 3 \%), 41 \mathrm{fs}\left(a_{0} \sim 0.8\right)$, and the plasma density was 2.5 or $3.7 \times 10^{18} \mathrm{~cm}^{-3}$. For relatively short discharge delay ( $t_{d}<130$ ns), significant red shift and moderate blue shift were observed, consistent with laser pulse modulation and exeroy deposition onto the plasma via wakefield generation. For longer discharge delay ( $\left.t_{d}>130 \mathrm{~ns}\right)$, the optical spectrum exhibited significant blue shift as well as red-shift, atd the transmission efficiency dropped.

The probability of observing any e-beams on the electron spectrometer in the range from 0.01 to $1.1 \mathrm{GEV}$ is shown in Fig. 7(b) by dashed lines. For $n_{0} \sim 2.5 \times 10^{1 \mathrm{~s}} \mathrm{~cm}^{-3}$, no electron beams were obstrved for $t_{d}<110 \mathrm{~ns}$ and trans- 

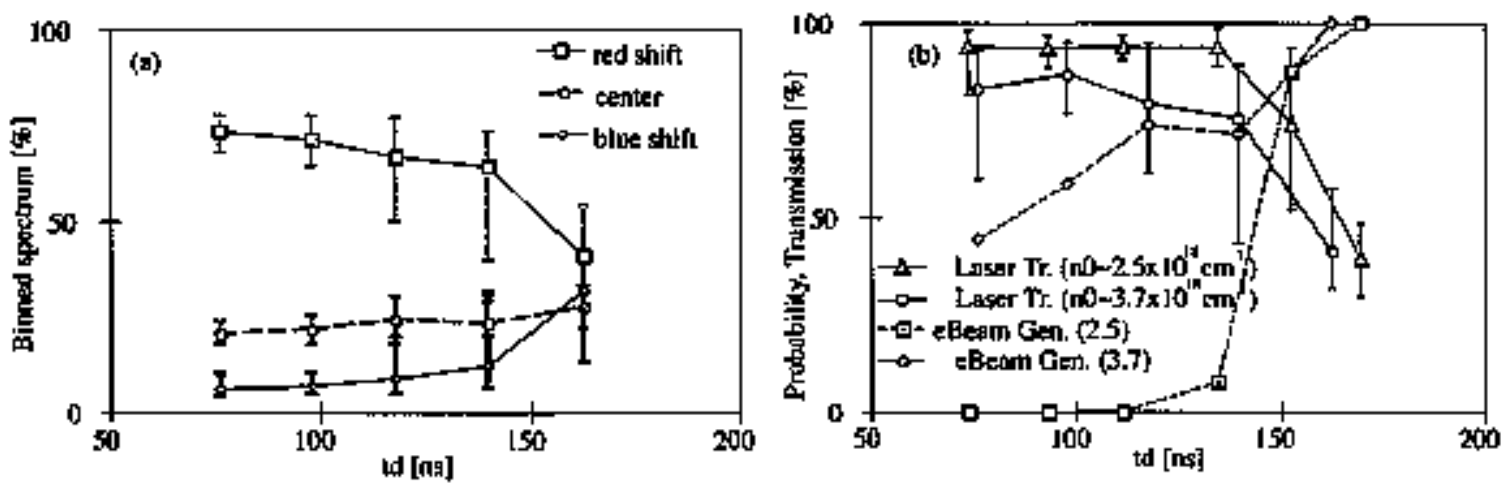

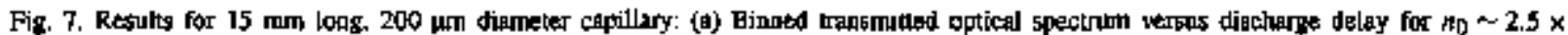
$10^{18} \mathrm{~cm}^{-3}$. The ceater ig defined as the light within the frequency bandwidth of $770 \leqslant \lambda \leqslant 835 \mathrm{~mm}$. The red (blug) shift is defined as $B 35<\lambda<[000 \mathrm{om}$ (320 $<\lambda<770 \mathrm{~nm})$. (b) Trangnission afficiency of laser pulses [solid line, triangles (circles\}) for $n_{0} \sim 2.5(3.7) \times 10^{18} \mathrm{~cm}-3$ ], and the probability of e-bagm observarion on the electron spectromeder [dashed lice, squares (dtamonds) for $160 \sim 2.5(3.7) \times 10^{18} \mathrm{~cm}{ }^{-3}$ ] versus

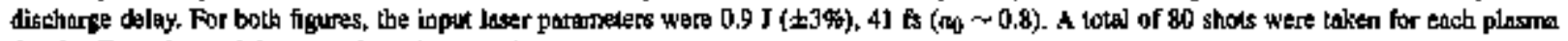
destity. Bars show minimum and mixtrum points.

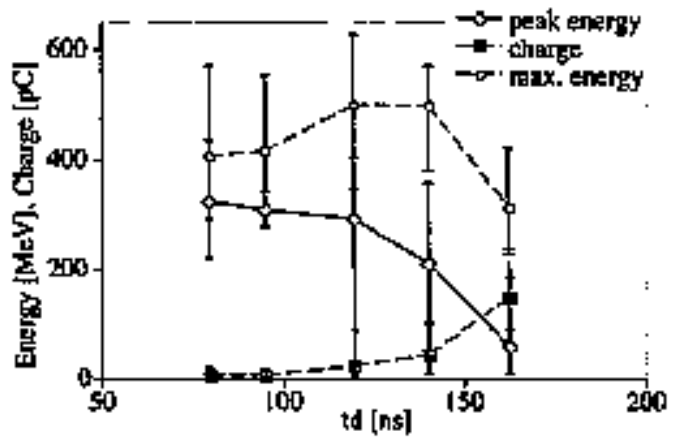

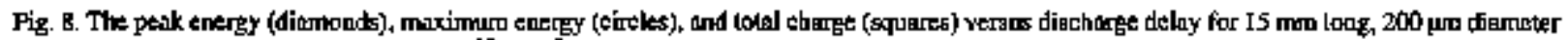

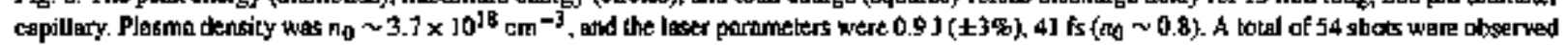
with ejectron beam. Bars ghow minimuma and maximam poimts.

mission efficiency was high ( $>$ \$0\%). This suggests that, although a wakefield was generated based on the observation of aignificant red-shift, it was not large enough to trap background electrons. Electron beams were abserved for longer discharge delay, along with a drop in transnyssion efficiency and enhanced blue sturt Note that by using higher density plasma $\left\{n_{0} \sim 3.7 \times 10^{18} \mathrm{~cm}^{-3}\right)$, e-beams were observed for shorter discharge delay without significant blue shift in transmitted optical spectrum.

The peak of the e-beam energy distribution (peak energy), te highest energy in the e-bean energy distribution (maximum energy), and total charge observed on the spectrometer versus discharge delay for $n_{0} \sim 3.7 \times 10^{18} \mathrm{~cm}^{-3}$ are shown in Fig. 8. One can see that relatively high energy (peak energy), low charge e-beams were observed with shorter discharge delay while low energy, high charge beams were observed with Ionger delay. For longer discharge delay, electron beams occasionally exhibit broadband, multiple peak structure, and significant low energy tail.

Several mechanisms could be jesponsible for the enhancement of blue shifting. laser transmission lobs, and electron tapping observed for longes discharge delay. For longer discharge delay, the amount of ionization, depth of the plasma channel, and plasma density decrease. It has also been suggesied that the amount of dischargt-ablaled material interacting with the laser pulse increased [24]. For a substantial amount of laser pulse energy to be blue shifted by ionization requires the peak intensity of the laser pulse to be within an order of magnitude of the ionization intensity of the ion species with which the pulse interacts. In the case of hydrogen this is $10^{14}-10^{15} \mathrm{~W} / \mathrm{cm}^{2}$, several orders of magnitude lower than the intensity of the laser in the channel. Ab)ated materials (e.g.-, aluminom, oxygen) have bigher ionization thresholds, and the deteriorated channel may lead to laser ablation of the capillary wall. Alturnalively, the blue shifting could be caused by photon acceleration of the back of the laser pulse [25], if it has stretched to a length of 

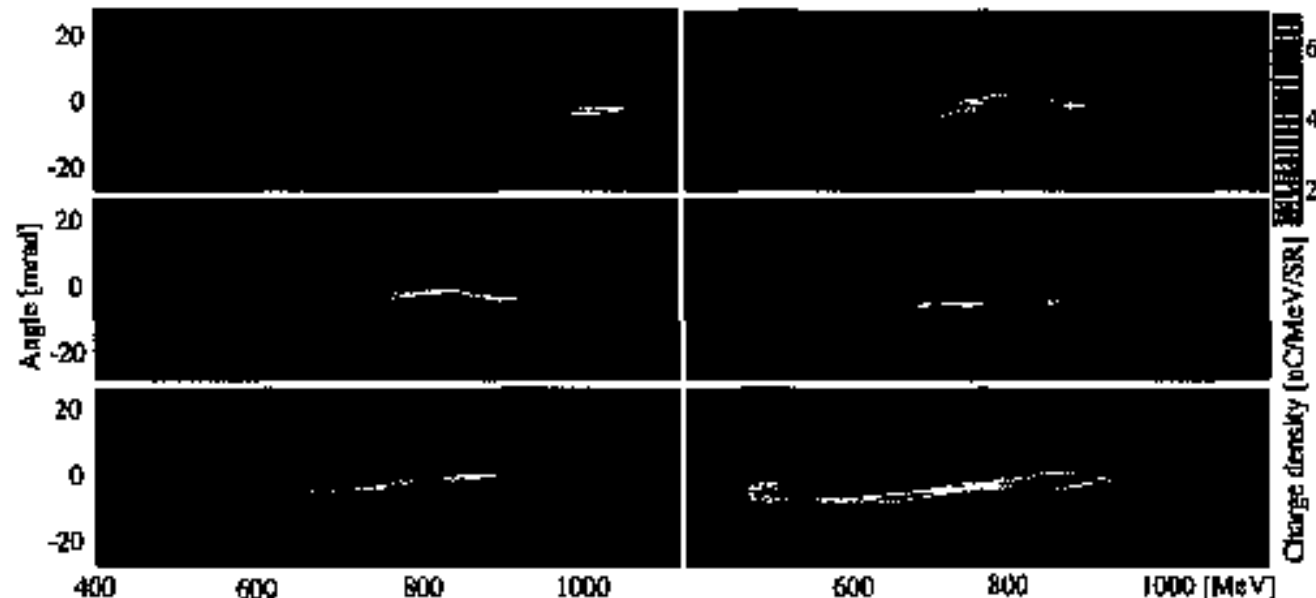

Fig. 9. Representalive tigh energy single shot e-beam spectra for a 33 mm long, 300 wy diandeter capillary. The plusth dengity was $\pi 0 \sim 5.3 x$ $10^{18} \mathrm{~cm}^{-3}$, and the laver paramaters were $1.5 \mathrm{~J}\left( \pm 5.7 \omega_{0} \mathrm{RMS}\right)$, $46 \mathrm{ts}\left(a_{0} \sim 0.8\right)$.

order the plasma wavelength. The rednced laser transmission was likely due to ionization (hydrogen and/or discharge ablated material) and laser leakage from the channel rather than stronger wakefield generation, because of the lower maximum energy observed for longer discharge delay. To explain enhanced trapping, recent studies suggested the interaction with a partially ionized plasma could assist seif-trapping [26,27]. Discharge-ablated materials drifting to the axis before the arrival of the laser could contribute to this process. Note that laser-ablated materials could not contribute to this process. Another possible explanation is an increase in the on-axis plasma density due to the deterioration of the chanmel. Although the amount of ionization decreases for longer discharge delay, the laser pulse was strong enough to ionize hydrogen, so that the on-axis density increases with delay time.

In 2006, generation of e-beams with energies of $1 \mathrm{GeV}$ was reported for a $33 \mathrm{~mm} \log$, $300 \mathrm{\mu m}$ diameter capillary with three gas slots $[5,6]$. Similar to those resulta, a parameter regime where c-beams with energies of op to $1 \mathrm{GeV}$ were produced was identifed for a $33 \mathrm{~mm}$ long, $300 \mu \mathrm{m}$ diameter capillary wilb two gas slots. Representalive single shot e-beam spectra are shown in Fig. 9. The plasma density was $n_{0} \sim 5.3 \times 10^{18} \mathrm{~cm}^{-3}$, the laser parameters were $1.5 \mathrm{~J}$ ( $(5.7 \% \mathrm{RMS}), 46 \mathrm{fs}\left(a_{0} \sim 0.93\right)$, and the discharge delay was $t_{d} \sim 580 \mathrm{~ns}$. In this parameter tegime, 51 shots were taken, and 37 shots produced electrons above $400 \mathrm{MeV}$. Average peak energy was $713 \mathrm{MeV}$, and average charge was $6 \mathrm{pC}$. Since e-beams were often observed with a low energy tail in this regime, only electrons with energy above $400 \mathrm{MeV}$ were taken into account for the antysis. The average laser transmission efficiency was $65 \%$. With this capillary, up to $70 \%$ ransmission efficiency was observed for 700 ns dischargo delay.

The peak energy and maximum energy versus total charge for a $33 \mathrm{~mm}$ long, $300 \mu \mathrm{m}$ diameter capillary are shown in Fig. 10. The peak energy showed clear dependence on the charge, whilt the maximum energy was somewhat insensitive to charge. One posscible explanation of this observation is the beam loading effect. The trapped electron bunch produces a wakefield which modifies the wakeneld generated by the laser pulse. For a short, higt charge bunch, the head-to-tail variation of the acceleraling field can be grealex than in the zero charge limit, leading to a larger bunch energy spread. Another possible explanation is that the higher charge beams were trapped over a large phase region in the plesma wave, essulting in a larger hesd-to-tail wake variation and a larger energy spread. To proctuce e-heams in a reproducible manner, controlling the amount and the location of electron trapping will be critical.

\section{Simolations of staged laser wakefield acceleration}

Experiments underway at LBNL are uow focusing on a staged LWFA approach in which a down-ramp electron injector is coupled to a capillary discharge plasma channel for acceleration to high energy [15]. Here we report progress on the design and physics of such a staged approached using the results of PIC simulations with the VORPAL [28] framework.

The low phase velocity that stabitizes and centrols trapping in down-ramp injection also causes rapid dephasing of the electron bunch, setting the $1 \mathrm{MeV}$-class maximum energy observed, and requiring injection of these bunches into 


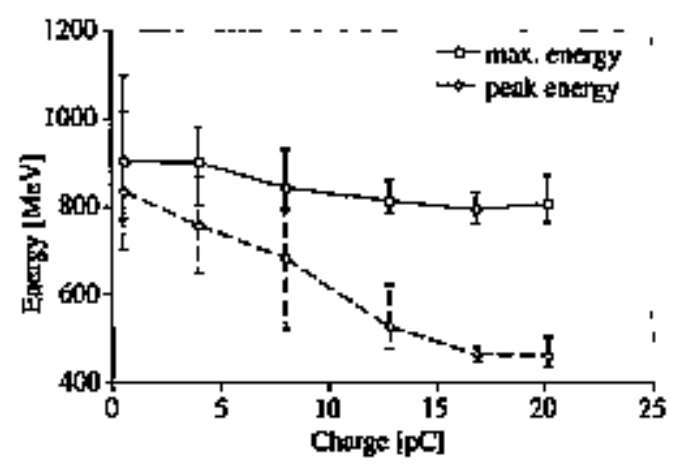

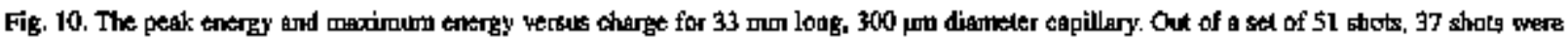

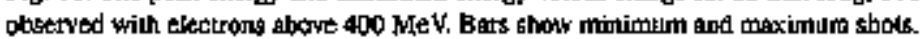
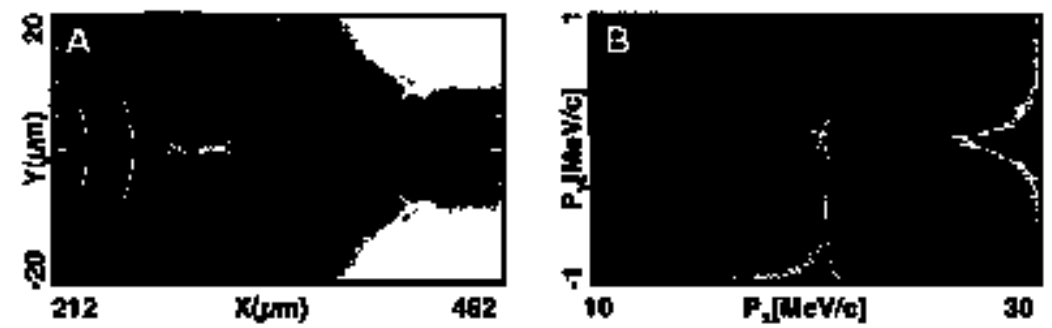

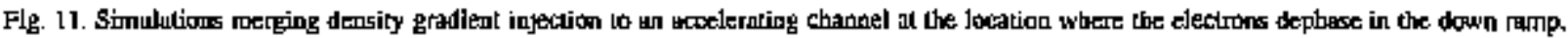

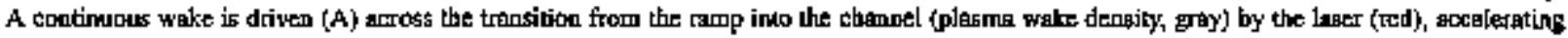

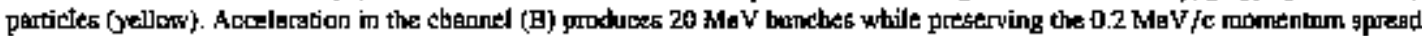

a subsequent LWFA stage to achieve bigh entrgy. As $\lambda_{p}$ lengthens in the down ramp, the buach expands to $\geqslant 50 \mu m$ in dimension, and this jength has been benchmarked to $\mathrm{THz}$ radiation measurements [29]. Use of the bunches as an injector therefore requires that the post-accelerating stage be directly coupled to the down ramp at the dephasing point, so that the bunch remains smaller than $\lambda_{j}$ in the post-accelerating stage. Use of such a conlinuous plasma in turn requires that the laser be well transmitted through the down ramp to drive the wake for post acceleration. Experiments [29,14] and simulations (Fig. I1) show that this requirement is met. The transmitted laser mode was similar to the vacuum mode, with no flamentation and with laser transmission of more than $70 \%$ when the jet was preionized by an 'ignitor' laser pulse arriving before the drive pulse (ignitor setup shown in [2!]).

Simulations eoding the down ramp in a plasma channel with uniform axial density intmediately after the particles are trapped show that the bunch is accelerated to high energy while preserying its low momentum spread (Fig. 11). Because the bunch is short compared to the plasma wavelength and because beam loading is not severe in this case, the variation of the accelerating field across the bunch is modest and its momentum spread is nearly preserved, producing $0.2 \mathrm{MeV} / \mathrm{c}$ class momentum spread at high energy. These simulations have so far shown acceleration to beyond $20 \mathrm{MeV} / \mathrm{c}$ (limited by computational time) with $0.18 \mathrm{MeV} / \mathrm{c}$ longitudinal and $0.15 \mathrm{MeV} / \mathrm{c}$ transverse momentum spread, corresponding to $<1$ \% energy spread and 510 mrad divergence. Longer and 3D simulations using the envelope model are in progress to optimize bunch quality. Additional simulations indicate that such post-acceleration nearly preserves absolute momentum spread, which may enable bunches at GeV energies and beyond with $<0.1 \%$ energy spread.

\section{Summary}

Research progtess at LBNL has been presented on (1) experiments on down-ramp injection ${ }_{+}$(2) experintents on acceleration in capillery discharge plasma channels, and (3) simulations of staged LWFAs. Experiments demonstrated that plasma gradient eontrol of injection in LWFAs producted bunches with 10- to 100-fold lower momentum spread and variation than previous laser accelerators, and demonstrated day-to-day stability over a week of run time. The bunches displayed central monentum of $0.76 \pm 0.02 \mathrm{MeV} / \mathrm{C}_{x}$ momentums spread in the longitudinal (transverse) 
direction of $0.17(0.02) \mathrm{MeV} / \mathrm{c}$ FWHM and poisting stability of $2 \mathrm{mrad}$ or $0.002 \mathrm{MeV} / \mathrm{c} \mathrm{RMS}$. Charge stability between 15 and $45 \%$ RMS was observed The simulated bunch size of $\sim 10 \mu \mathrm{m}$ long by $5 \mu \mathrm{m}$ diameter, together with the experimental and simulated divergences ( 20 mrad FWHM), implies a nombalized emittance on the order of

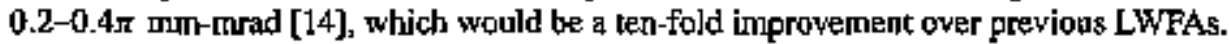

Relativistic electron beam generalion via a capillary dișcharge guided LWFA was studied by using $15 \mathrm{~mm}$ long, $200 \mu \mathrm{m}$ diameter and $33 \mathrm{~mm}$ long, $300 \mu \mathrm{m}$ diameter capilaries. Generation of quasi-monoenergetic e-beams up to $300 \mathrm{MeV}$ was observed from the $15 \mathrm{~mm}$ long capillary, and up to $1 \mathrm{GeV}$ was observed from the $33 \mathrm{~mm}$ long capillary. By using longer discharge delay, self-trapping was stabilized for the $15 \mathrm{~mm}$ long, 200 um diameter capillary. This regime could be used to desigms a stable self-injected, capiliary discharge guided LWFA. While reproducible beams have been observed in tightly conscolled parameter regime, a controlled mechanisut for injection will be important 10 enhance LWFA performance.

Simulations benchmarked to the experiments showed that by covpling bunches from a down-ramp injector to subsequent channel-guided stages, the low absolute momentum spread was preserved as the bunch accelerated, resulting in high energy beams with $0.2 \mathrm{MoV} / \mathrm{c}$ momentum spread and low emittance. This may allow bunches at GeV energies and beyond with $<0.1 \%$ energy spread. Together with the observed stability over many run days, these properties will benefit many LWFA applications.

\section{Acknowledgements}

This work was supported by the Director, Office of Scieace, High Energy Physics, U.S. Department of Energy under contracts DE-AC02-05CH11231, DE-FC02-07ER41499, DE-FG02-06ER84484, DE-FG03-95ER40926, DEFG02-01ER41178, DE-FG02-03ER83857, DOE SciDAC, NERSC, and ATLAS programs, National Science Foundation contracts 0113907 and 0614001 , and DARPA. We appreciate the contributions of J. van Tilborg, D. Syversrud, J. Wallig, and N. Ybarrolaza.

\section{References}

[1] For a review, seg E. Esarey, et al, IEEE Trans, Plasm Sci. 24 (1996) 252-288.

[2] CGR. Geddes, et al, Nature 431 (2004) 538-541.

[3] S.P. D. Mangles, ed al, Nature 431 (2004) 535-538.

[4] J. Fonure, tt all. Neture 431 (2004) 54I-544.

[5] W.P. Leemans, th t. Nal. Phys. 2 (2006) 696-699.

[6] K, Nakamura, el al., Phys. Plasmas 14 (2007) 056708.

[7] C.G.R. Geddeg, et al., Phys. Plasmas 12 (2005) 056709.

[8] C.-T. Hsirich, et al., Phys Rev. Lett 96 (2006) 0,5001.

[9] E. Estrey, tt al_ Ptrys. Rev. Leth. 79 (1997) 2682-2685.

[10] G. Fubient, et al., Phys. Rey. E 70 (2004) 016402.

[11] H. Kotaki, th al., Phys. Piesmes 11 (2004) 3296-3302.

[12] S. Bulanow, en al., Pays. Rev. E 58 (1998) R5257.

[I3] J. Faure, et al., Nature \$44 (2006) 737-739.

[14] C.G.R. Geddes, el al., Phys. Rew. Leth 100 (2008) 215004.

[15] A J.W. Reitstik a al., Phys. Rey, ST-AB 5 (2002) 051301.

[16] R.G. Hamker, N.M. Hatz, M. Uegaka, Pbys. Rev. ST.AB 5 (2002) 041301.

[1]] H. Suk, N. Barow, J.B. Rosenzrieig, E. Esary, Phys. Rev. Lett. 86 (2001) 1011.

[18] Y. Pelrilla, L. \$crafini, P. Tomegsini, Phyg. Rex. \$T-AB l I (2008) 070709/l-7.

[19] LOASIS facility (LBNL): hutp://latisis.lb].govt.

[20] For BPS dala, a second laper pwlse (2 TWW was prefent from other experiments. Bunch properties were indepeadent of ils pointlog. Spectromter daba (no ascond leser), verified the second lager did not affect the bunct.

[21] C.G.R. Geddes, a al., Phys. Rev, Leth 95 (2005) 145002.

[22] A.J. Gonsalyes, th al.. Phys. Rey. Letc 98 \{2007) 025002.

[23] K. Nakantura, el al., Rev. Sci. Inturim. 79 (200B) 05330 ].

[24] A.J. Gonsalyes, PhD. thesls, University of Oxford, 2006.

[2]] CD. Murphy, et al., Pays. Plasmas I (2000) 033 I0B.

[26] T.P. Row lands-Rees, et al, Phys. Rev, Lett. 100 (2008) 105005.

[27] E. Oz, el al, Phyб Rev. Lett. 98 (7006) 0848Dl.

[2B] C. Nieter, J. Cary, J. Comp. Phys. $196\{20004\} 448-47\}$.

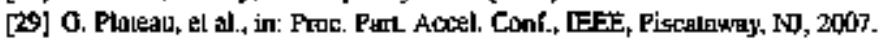

